\title{
Mulemba
}

Revista Angolana de Ciências Sociais

\section{Revisitando uma obra exemplar: Dialectic of enlightenment: philosophical fragments de Theodor Adorno e Max Horkheimer}

\section{Cesaltina Abreu}

\section{(2) OpenEdition}

\section{Journals}

Edição electrónica

URL: http://journals.openedition.org/mulemba/316

DOI: $10.4000 /$ mulemba.316

ISSN: 2520-0305

\section{Editora}

Edições Pedago

\section{Edição impressa}

Data de publição: 1 novembro 2014

Paginação: 641-658

ISSN: 2182-6471

Refêrencia eletrónica

Cesaltina Abreu, «Revisitando uma obra exemplar: Dialectic of enlightenment: philosophical fragments de Theodor Adorno e Max Horkheimer», Mulemba [Online], 4 (8) | 2014, posto online no dia 20

novembro 2016, consultado o 26 janeiro 2021. URL: http://journals.openedition.org/mulemba/316 ; DOI: https://doi.org/10.4000/mulemba.316

Este documento foi criado de forma automática no dia 26 janeiro 2021.

Tous droits réservés 


\title{
Revisitando uma obra exemplar: Dialectic of enlightenment: philosophical fragments de Theodor Adorno e Max Horkheimer
}

\author{
Cesaltina Abreu
}

\section{NOTA DO AUTOR}

Theodor Adorno e Max Horkheimer, Dialectic of enlightenment: philosophical fragments. Editado por Gunzelin Schmid Nörr, baseado no texto definitivo das obras completas de Max Horkheimer; traduzido do alemão por Edmund Jephcott. Stanford, Stanford University Press, 282p. As transcrições em itálico ao longo do texto são tradução da autora desta leitura crítica.

\section{Argumento}

1 A obra trata de temas actuais relacionados com a ética, a estética e o conhecimento, numa abordagem crítica sobre o esclarecimento na história da humanidade - com especial incidência na ênfase que lhe foi atribuída pela revolução burguesa -, entendido como processo de dominação progressiva da natureza. Contudo, devido à forma como foi conduzido, originou um novo estágio de barbárie porque, ao invés de produzir uma humanidade livre de superstições e mitos, acabou produzindo novos mitos que formatam as relações sociais. Mais, em vez de permitir uma convivência mais adequada entre o Homem e a natureza, conduziu a processos de exploração desenfreada dos recursos naturais. Não só não conduziu a um estágio de desenvolvimento caracterizado por relações sociais mais justas e livres de preconceitos como racismo, papel subalterno da mulher na sociedade, produção e reprodução de 
representações do corpo e do imaginário das pessoas, que alimentem o potencial emancipatório do ser humano, como produziu a massificação cultural. Esta alimenta a alienação crescente das relações do Homem com a natureza e consigo próprio, tendo como pano de fundo a exploração desenfreada dos recursos naturais para alimentar a expansão do sistema capitalista, reproduzir as desigualdades sociais e manter o status quo, gerando o desencantamento do mundo (p. 1). Em ambiente democrático e liberal, este objetivo tem sido alcançado mantendo a população em estado de ignorância ao serviço dos interesses do sistema de dominação económica, e legitimado pela sua incorporação nos sistemas de valores dominantes.

2 Para os autores, a dialéctica do esclarecimento parece significar a interpenetração entre cultura e barbárie, como característica distintiva da civilização ocidental. Algumas ideias parecem fundamentais no argumento dos autores. Uma, a de que o desenvolvimento da ciência em vez de libertar o conhecimento de mitos e superstições, produz novos mitos e novas superstições que limitam a capacidade de compreensão dos fenómenos e a intervenção das pessoas. Outra, a da subversão do papel da cultura e da arte, realizada pelos meios de comunicação massiva, que esvaziaram o conteúdo das palavras, dispersando-o em sons, imagens e alegorias reproduzidos de forma abrangente, com a intenção de domesticar o potencial emancipatório da natureza humana e de naturalizar a instrumentalização dos recursos naturais para alimentação do sistema capitalista. Directamente relacionada com esta, a ideia de que os meios de comunicação massiva, incluídos no que designam de indústria cultural, operam através de mecanismos manipuladores e opressivos, apesar de se atribuírem e veicularem uma finalidade cultural ao serviço do progresso da humanidade, no sentido distorcido do termo, porque significa o domínio da natureza. Outra ideia nuclear do argumento considera o processo de esclarecimento como uma continuidade desde os primórdios da história da humanidade, produzindo ciclicamente novos mitos e novas superstições à medida que o desenvolvimento da ciência permite a superação dos patamares de inquietações que dominam as pessoas. 0 mito vira esclarecimento e o esclarecimento reverte à mitologia: este paradoxo é a tese fundamental do livro.

\section{Contexto}

3 A obra é escrita por dois filósofos de esquerda cuja formação foi profundamente marcada pelo marxismo e que procuraram uma articulação entre a teoria marxista e as respostas para os principais fenómenos da vida social, não apenas na Alemanha, mas no mundo em geral, assumindo o pressuposto marxista que toda a teoria social deve ser eminentemente crítica e transformadora da realidade. Esta articulação seria resultado de um aprofundamento das teses marxistas, através da realização de estudos e debates no âmbito de um Instituto para a Pesquisa Social, que nasceu com o objectivo de estudar o marxismo. De entre os temas mais debatidos pelo Instituto contam-se os relacionados com a produção e recepção de bens culturais no âmbito do sistema capitalista. Os autores são ambos alemães de origem judaica, e encontravam-se exilados nos Estados Unidos quando escreveram a obra.

No prefácio à segunda edição alemã, os autores não apenas sustentaram a argumentação inicial, porque na perspectiva deles as ideias defendidas permaneciam actuais, como consideraram que elas serviram de base ao desenvolvimento de trabalhos 
posteriores, que continuavam articulados com a busca pela compreensão do processo de transição para o mundo administrado, e desencantado. ${ }^{1}$

Contudo, e apesar de uma possível leitura pessimista da obra, os autores defendem a ideia da possibilidade de desenvolvimento do pensamento crítico alicerçado nos últimos resíduos de liberdade «pelas tendências ainda existentes de uma humanidade real, mesmo que pareça impotente face à grande marcha da história». ${ }^{2}$ Por outro lado, o retorno deles à Alemanha após a Segunda Guerra Mundial alimentado pela «convicção de que aqui poderemos fazer mais do que em qualquer outro lugar», ${ }^{3}$ transmite a ideia de que a crise gera oportunidades para a sua superação, ou seja, numa sociedade profundamente marcada por duas derrotas humilhantes nas guerras mundiais e destruída tanto no seu tecido social quanto na sua infraestrutura física e institucional, é possível lutar pelo ideal da preservação da liberdade, ampliando-a e desdobrando-a, e opondo-a, de alguma forma, à progressão do mundo administrado.

\section{Influências}

6 A proposta de realização de uma aproximação entre filosofia clássica e as ciências humanas, entre as quais a recente (à época) psicanálise, manifesta uma profunda influência de filósofos do Iluminismo, particularmente Kant, mas também Hegel, Nietzche, Freud e, de forma muito evidente, Marx. Contudo, outros filósofos como o Marquês de Sade e Bacon são chamados ao diálogo pelos autores, em diversas passagens da exposição do seu argumento.

\section{Desenvolvimento das ideias da obra}

\section{0 conceito de esclarecimento}

7 Se por «esclarecimento» se entende o processo de livrar a humanidade do medo ancestral em relação às forças inexoráveis da natureza e dos preconceitos em relação à diversidade e, com isso, eleva-la a um estágio superior de evolução onde mitos e crendices deixassem de povoar o imaginário das pessoas, a análise da história demonstra que a humanidade continua presa de mitos e superstições, porque esse processo de esclarecimento tem conduzido a sucessivos novos tipos de barbárie. E isto acontece devido à auto-destruição do esclarecimento, no sentido em que «ele não acolhe dentro de si a reflexão sobre os elementos de regressão, sobre os elementos destrutivos do progresso [...] perdeu o seu carácter superador e, por isso, também a sua relação com a verdade» (pp. 6-7) Estes dois aspectos são relacionados porque «na sociedade, a liberdade é inseparável do pensamento esclarecedor» (p. 7) porque os indivíduos se vêm completamente anulados perante o poder económico. À medida que aumenta a produção de bens materiais, criam-se condições para uma maior justiça e equidade, contudo esse aumento de produtividade tem sido acompanhado de um aumento dos mecanismos de controlo dos grupos sociais dominantes sobre os grupos dominados. Estes sentem-se simultaneamente impotentes perante o crescente poder daqueles, e condicionados nas suas capacidades e modos de agir pelo pensamento dominante, que adopta estratégias diversas, desde a criação de tabus relativamente a certas questões, o falseamento da clareza de outras, a produção e difusão de uma enorme quantidade de 
informações precisas em relação a outras questões, poucas e restritas, consideradas inócuas do ponto de vista da manutenção das relações de dominação.

8 No entender dos autores, o esclarecimento esteve sempre intimamente relacionado com a coerção social, mesmo durante o liberalismo. A unidade da colectividade manipulada ${ }^{4}$ consiste na negação de cada indivíduo, não representando uma recaída nem algo momentâneo, mas antes o «triunfo da igualdade repressiva, a realização pelos iguais da igualdade do direito à injustiça» (p. 9), dando como exemplo a juventude hitleriana.

O resultado é a progressiva alienação dos indivíduos em relação a si próprios e em relação à natureza, a par do aumento progressivo do controlo sobre as coisas e a natureza. É a desistência de procurar um sentido para a vida, acompanhada de um consentimento na exploração sistemática dos recursos naturais. A alienação em relação a si próprio transfere-se para as relações humanas e sociais, despindo-as de outro sentido que não seja o da reprodução e extensão do predomínio humano sobre a natureza: se antes os indivíduos acreditavam poder intervir na natureza através dos feitiços e rituais, agora o conhecimento científico, incorporado nas técnicas, permite à humanidade intervir nos processos naturais, «domesticando-os».

Para os autores, esta ideia produzida hoje pelo conhecimento científico, existe desde a antiguidade embutida nos mitos. Contudo, a diferença existente entre ciência e mito reside no facto de a primeira não recorrer à representatividade específica, por exemplo, o objeto ou parte do objeto que representa a pessoa-alvo da prática de feitiçaria ou do ritual. O método de produção de conhecimento científico recorre ao conceito de fungibilidade universal, o que permite considerar a molécula de um elemento químico, reconhecida como tal, em qualquer lugar do mundo, porque o que é valorizado é o método, a utilização do trabalho de outros, o capital. o que aproxima o conhecimento científico do mito é o carácter de repetição: a temporalidade cíclica do mito é um equivalente funcional da experiência científica que pode ser repetida ad infinitum sempre com o mesmo resultado.

11 Neste sentido, mais importante do que a verdade seria o método, o procedimento eficaz, pois segundo os autores, o objectivo e a função da ciência é «[...] descobrir particularidades antes desconhecidas, para melhor prover e auxiliar a vida» (p. 20). Por outras palavras, é o que eles designam de «desencantamento do mundo» e não a produção de discursos que provoquem prazer, inspirem respeito ou impressionem. Os seres humanos renunciaram ao sentido incorporado na palavra: outrora, a palavra não era tão especializada quanto é na actualidade. Essa especialização foi realizada pela evolução da ciência e da técnica; quando o entendimento entre as pessoas e a expressão da racionalidade usava o discurso como mecanismo de argumentação, informação e recepção de ideias e sentimentos, a palavra situava-se no âmago de um processo interactivo de comunicação de sentido, imagem e som, tudo traduzido por palavras. 0 desenvolvimento da racionalidade proporcionado pela ciência e incorporado na técnica operou o fraccionamento desta unidade de sentido em diversas dimensões isoladas entre si, esvaziando a palavra dos sentidos de imagem e de som, restando-lhe o seu significado literal. Esta fragmentação do sentido da palavra é considerada pelos autores como uma espécie de divisão do trabalho espiritual: como signo, a palavra relaciona-se com a ciência, como som, imagem e em seu sentido literal, ela distribuiu-se entre as várias artes, como pintura, música, poesia, etc. Como a ciência é cada vez mais vista como o meio de garantir a auto-preservação humana, é a arte relegada para um plano 
secundário, porque não contribui para esse objetivo em torno do qual se concentram as atenções.

Retomando o argumento kantiano de que a limitação do conhecimento resulta da dimensão do espaço atribuída à fé, os autores consideram que a limitação do saber operada pela burguesia não se traduziu num maior espaço para a arte, mas sim para a fé, através da qual se busca a reconciliação do espírito com a vida. Neste ponto, os autores apresentam dois argumentos relacionados com a arte e a cultura. Por um lado, chamam a atenção para o facto de a civilização europeia ter sempre tratado a beleza (estreitamente relacionada com a arte) com a ambiguidade resultante da sua subvalorização enquanto instrumento para garantir a auto-preservação e, por isso mesmo, o belo é também considerado perigoso, na medida em que é um meio de subversão da primazia da sobrevivência material sobre o prazer espiritual. Por outro lado, estabelecem uma comparação entre arte verdadeira e arte leve: em decorrência da dispersão dos signos da palavra pelas distintas artes, apenas as obras de arte verdadeiras conseguiram escapar à imitação daquilo que já existe, remetendo o desenvolvimento desta ideia para a discussão sobre a industrialização cultural.

Numa crítica a Durkheim, os autores consideram que o caráter social das formas de pensamento não é expressão de solidariedade mas representa a unidade entre dominação e sociedade. Desde a separação entre o poder e a obediência operada pelas distintas etapas de concretização da divisão do trabalho «o poder de todos os membros da sociedade, que nessa condição não têm outra saída, acaba sempre, pela divisão do trabalho a eles imposta, por se agregar no sentido justamente da realização do todo, cuja racionalidade é, assim, mais uma vez multiplicada. Aquilo que acontece a todos, por obra e graça de poucos, realiza-se sempre como a subjugação dos indivíduos por muitos: a opressão da sociedade tem sempre um carácter da opressão por uma colectividade. É essa unidade entre colectividade e dominação, $e$ não a universalidade social completa, a solidariedade que se sedimenta nas formas de pensamento» (p. 16).

14 Para os autores, a máxima de Spinoza «o esforço para se conservar a si mesmo é o primeiro $e$ único fundamento da virtude» (p. 22) pode ser alargada na sua abrangência e ser considerada como o eixo central do desenvolvimento da civilização ocidental, pois segundo o juízo do esclarecimento «[...] aqueles que se entregam directamente à vida sem qualquer referência racional à auto-preservação regridem à pré-história». Por outro lado, o trabalho social é orientado pelo princípio do «eu» na economia burguesa capitalista e «[...] quanto mais o processo de auto-preservação se baseia na divisão burguesa do trabalho, tanto mais ele reforça a auto-alienação dos indivíduos que devem moldar-se ao corpo e alma do aparato técnico» (p. 23). A coisificação do sujeito, resultante da eliminação da consciência no decurso do processo técnico, permite que a razão seja usada como um instrumento universal para fabricação dos demais instrumentos, ou seja, a razão funcionando enquanto «puro instrumento dos fins» (p. 23).

Os autores recorrem a uma alegoria da história, o encontro de Ulisses com as sereias, para argumentar que a tentação pelo canto das sereias representa a tentação de deixarse perder pelo que já aconteceu e que no processo de enfrentamento de tais tentações - representando o poder das forças da natureza - o sujeito fortaleceu o seu ego e a sua identidade através da utilização da energia dessas forças contra elas próprias, o chamado efeito boomerangue.

16 A consistência da alegoria histórica reside no fato de a civilização ocidental ter sempre manifestado uma tendência inexorável para a transformação de meios em fins. Em 
outras passagens da Odisseia, o herói que renunciara temporariamente à sua identidade para salvar a vida, sente uma necessidade vital de a afirmar perante todos, mas principalmente perante si mesmo, embora correndo o risco de ser capturado de novo. Esta alegoria do encontro entre Ciclope e Ulisses na selva, relaciona-se com a conviç̧ão dos autores de que a debilidade dos sujeitos não é apenas física mas também do «ego». Noutra passagem, a alegoria representa a posição subalternizada da mulher na civilização ocidental: com a ajuda do Deus Hermes, Ulisses não apenas escapou ao encantamento de Circe - que enfeitiçava os homens chegados à Ilha de Eéia com uma bebida que os transformava em porcos -, como a fez apaixonar-se por ele e submeterse às suas ordens. Qualquer destes recursos alegóricos visa demonstrar o modus operandi do processo de esclarecimento unilateral, não dialético.

\section{0 relacionamento entre trabalho, mito e dominação}

17 Este entrelaçamento é representado pela alegoria histórica do encontro entre Ulisses e as sereias. 0 sujeito torna-se o herói que resiste à tentação de voltar para trás, que não se deixa trair pelas suas ilusões, e que se submete ao sofrimento como forma de se emancipar para vencer o medo da morte e da destruição, o outro lado da moeda da promessa da felicidade. Consistindo «o caminho da civilização na obediência e no trabalho», Ulisses coloca em prática a estratégia de salvação: ele coloca cera nos ouvidos dos seus companheiros para que, ficando surdos, resistissem ao canto das sereias e continuassem a remar num ritmo que logo os levasse para longe dali, reservando-se o direito de usufruir o prazer de ouvir o canto; entretanto, porque estava consciente do perigo que corria, fez-se amarrar a um poste para não ser atraído e hipnotizado: esta alegoria representa não apenas a reprodução das condições de opressão na divisão do trabalho, mas também a separação da fruição artística do trabalho manual. Se os companheiros ensurdecidos de Ulisses - que ignoram os seus gestos para o soltarem, continuando a remar porque não desfrutam do prazer de ouvir o canto encantado das sereias, e assim se salvarem, salvando também a vida do seu opressor - representam a grande maioria a quem cabe a tarefa de «tocar o barco para a frente», ao escutar imóvel o canto das sereias Ulisses representa o público que, deleitado, assiste aos concertos de música, porque tem tempo e disponibilidade para isso, uma vez que os seus «comandados» continuam produzindo para si. Surdez nos dominados e imobilidade do dominador, os servos dominados no corpo e na alma, enquanto o senhor regride porque «nenhuma dominação conseguiu ainda evitar pagar esse preço, e a aparência cíclica da história em seu progresso também se explica por semelhante enfraquecimento, que é o equivalente do poderio [...] a adaptação ao poder do progresso envolve o progresso do poder, levando sempre àquelas formações recessivas que mostram que não é o malogro do progresso, mas exatamente o progresso bem-sucedido o culpado do seu próprio oposto».

18 Entretanto, outro aspecto relevante nesta alegoria diretamente relacionado com as relações de trabalho e de dominação, é a representação da situação da cultura e da arte no mundo administrado: apenas uma pequena minoria pode consumir o artigo de luxo designado arte, que contudo se encontra imobilizada, sem poder se mover. A grande maioria é excluída do usufruto do prazer proporcionado pela arte, sem qualquer hipótese de adquirir uma noção, ainda que mínima, da beleza do canto, pois estão condicionados à execução inapelável das tarefas de reprodução do sistema, que lhes 
cabem pela divisão do trabalho, o que, no entender dos autores, representa que o "património cultural encontra-se em exacta correlação com o trabalho».

Todos as aspectos referidos concorrem para caracterizar o que os autores designam de «emergência da natureza não-reconciliada», ou seja, a manifestação na sociedade humana da rigidez e inexorabilidade do substracto natural que, desde o início, a humanidade pretendeu submeter ao seu domínio. Apesar da produção pela ciência dos meios tecnológicos hoje ao dispor da humanidade e que lhe permitem dominar a natureza, a barbárie que a ela se associa emerge no âmbito das relações humanas.

\section{0 relacionamento entre esclarecimento e moral}

Os autores recorrem a mais uma alegoria para estabelecer a relação entre esclarecimento e moral, começando por uma crítica à concepção kantiana de esclarecimento como "a saída do ser humano da sua menoridade, da qual é o próprio culpado. A menoridade é a incapacidade de se servir do seu entendimento sem a direcção de outrem» (p. 63), em que «outrem» significa «razão». Por outras palavras, a percepção do ser humano é formada em relação ao entendimento que tem das coisas o que, segundo os autores, recorre a um "esquematismo» que imprime na coisa a qualidade objetiva que o juízo subjectivo nela encontra, operando a adequação da impressão ao conceito, da categoria ao exemplar, e conferindo unidade ao pensamento, sendo tarefa consciente da ciência produzir tal unidade. Contudo, as condições da vida não são as condições do laboratório, o que leva a que o pensamento não consiga harmonizar o sistema com a intuição, o que provoca um conflito entre ele e a vida prática, com o inesperado ocorrendo e o aguardado não acontecendo. Atendendo a que os princípios do sistema são os da auto-conservação, apoiando o sujeito na dominação da natureza, a menoridade revela-se como a incapacidade de se conservar a si mesmo.

Para os autores, o burguês senhor de escravos, empresário livre ou administrador, é o sujeito lógico do esclarecimento. Segundo eles, a ambiguidade dos conceitos kantianos manifesta-se no fato de que, por um lado a razão contém a ideia de um convívio em liberdade que permita aos seres humanos organizarem-se enquanto sujeito universal superando, através da solidariedade, o conflito entre a razão pura e a empírica: essa ideia representa a utopia, a verdadeira universalidade. Por outro lado, a razão constitui o princípio organizador do pensamento dirigido para a auto-conservação, excluindo outros motivos que não a subjugação do material. A verdadeira natureza do «esquematismo» revela-se como o interesse da sociedade industrial na qual tudo, incluindo o ser humano, é considerado um processo reiterável e substituível, mero exemplo para os modelos conceituais do sistema. As consequências deste «esquematismo» são vistas pelos autores como um condicionamento dos sentidos pelo aparelho conceitual mesmo antes da ocorrência da percepção, ou seja, o sujeito vê o mundo tal como ele o produz para si próprio. Trata-se de um mecanismo de «censura» intuído por Kant e que viria a ser realizado pela indústria cinematográfica americana: a produção das imagens já é condicionada por uma pré-censura que resulta dos padrões de entendimento vigentes que irão determinar a forma como elas, mais tarde, serão vistas. Trata-se de um condicionamento ditado pelos fins, tal como acontece com a ciência.

Considerando que a ciência é um instrumento, enquanto «o esclarecimento é a filosofia que identifica a verdade do sistema científico» (p. 66), os autores afirmam que a ideia de auto- 
compreensão da ciência, defendida por Kant, contradiz a ideia da própria ciência que, por se tratar de um exercício técnico, está tão distante de uma auto-reflexão sobre os seus próprios fins quanto as outras formas de trabalho sob pressão do sistema. Por essa razão, entendem os autores, a obra de Kant tem sido acusada de dogmática.

Apenas o Marquês de Sade apresenta na sua obra «o entendimento sem a direcção de outrem» (p. 68), o que lhe permite extrair consequências dos pressupostos da sociedade moderna, entre os quais, que o conhecimento científico aplicado como tecnologia a objetivos económicos imediatos se transformou na norma central da civilização europeia, o que retira não só a importância, mas também a validade das crenças e fé religiosas que, por essa razão, deveriam ser combatidas. Recorrendo aos exemplos das equipas desportivas em que cada membro tem noção clara de seu papel e também tem um suplente, os autores introduzem a alegoria da Juliette e seus parceiros e parceiras praticando todas as formas de sexualidade desaprovadas pela sociedade, não pelo prazer que delas pudessem retirar, mas pelo fato de considerarem que, sendo mitos, devem ser superados. Por outras palavras, a filosofia burguesa tinha como objetivo libertar os humanos das influências da doutrina católica do «ordo» e da religião popular pagã, mas esse objetivo foi extrapolado: se, anteriormente, ao cabo de cada fase de mudança, novas mitologias (ainda que esclarecidas) substituíam as anteriores, sob o emprego da razão levada às ultimas consequências, todos os vínculos previamente dados sucumbiram à imposição de tabus, lançando os actores num ambiente de hipocrisia. Isso permitiu à filosofia não só proclamar as virtudes burguesas e a filantropia, como enaltecer, como virtudes, a autoridade e a hierarquia, as quais já haviam sido reconhecidas como mentiras pelo esclarecimento. Neste sentido, os escritores «sombrios» - em oposição aos escritores e filósofos do iluminismo -, entre os quais o Marquês de Sade, não tentaram distorcer as consequências do esclarecimento com recurso a subterfúgios de «doutrinas harmonizadoras» (p. 93), não pretenderam que a razão tivesse uma ligação mais íntima com a moral do que com a imoralidade, e anteciparam os vícios privados como virtudes públicas, tomando a «ciência ao pé da letra» e proclamando a identidade da dominação e da razão.

\section{A indústria cultural}

Começando por afirmar que «a cultura contemporânea confere a tudo um ar semelhante» e que «a rádio, o cinema e as revistas constituem um sistema» (p. 94), os autores introduzem dois elementos importantes do argumento da segunda parte do livro, ou seja, a criação da indústria cultural, em que o esclarecimento surge como a «mistificação das massas».

Com o declínio da religião não se verificou o esperado caos cultural, na medida em que o «sistema» substituiu-a enquanto formador e organizador da opinião pública. Para os autores o sistema funciona com base numa "falsa identidade do universal e do privado», exemplificada na arquitectura urbana. Os grandes edifícios são o símbolo das grandes corporações e os pequenos apartamentos em complexos densos e bem organizados, dando um ar de autonomia ao indivíduo e de harmonia do particular com o todo em que ele se insere, mas na verdade tornam-o cada vez mais sujeito ao poder do capital, porque a sua dupla função é a de gerar enquanto facilita o controlo social.

Se por um lado a cultura se auto-denomina de «indústria», adotando os seus métodos e modos de produção, por outro lado este aspecto inédito da cultura na história da humanidade encontra a sua comprovação nos resultados financeiros apresentados pela 
nova indústria, que se mostra tão ou mais produtiva do que as demais indústrias de outros ramos; isto subentende que os seus produtos são alvo de uma procura generalizada e em crescimento. Entretanto, os padrões da maioria de seus produtos revelam-se de muito baixa qualidade. Segundo a lei da oferta e da procura, e atendendo ao sucesso e à influência crescente que estes produtos vêm ganhando junto do grande público, a padronização teria então resultado da incorporação da procura desse público por esse tipo de produto, reflectindo as suas necessidades. Ou seja, a sua ampla aceitação significaria que eles seriam adequados aos gostos e preferências dos consumidores. Mas os autores refutam este argumento, considerando que «o que o explica é o círculo da manipulação e da necessidade retroactiva, no qual a unidade do sistema se torna mais coesa» (p. 95), ou seja, o sistema responderia às necessidades iniciais do público consumidor, mas de uma forma tal que se apropria deles para cumprir os seus objetivos e a sua função no âmbito da economia actual.

Uma das técnicas a que o sistema recorre é a da organização do seu público em categorias de consumo e de capacidades de pagar, relativamente às quais é organizada a produção hierarquizada em termos de uma qualidade que não tem a ver com o conteúdo dos produtos, mas com as «classes» de consumidores a que se destinam, no verdadeiro sentido da palavra classe, ou seja, um conjunto de pessoas com determinadas características sociais, económicas e políticas, que manifestam em geral preferências próximas e que manifestam comportamentos mais ou menos idênticos em relação aos mesmos estímulos. Trata-se, pois, de uma cultura «em pacote» destinada a um grupo específico de consumidores.

Recorrendo uma vez mais ao «esquematismo» das pessoas - procedimento mental de referirem as suas percepções a conceitos fundamentais designados de "categorias» por Kant -, para explicar o procedimento através do qual o sistema dele se apropria, decompondo nas suas partes constitutivas e colocando em circulação as informações sob a forma dos arranjos que pareçam os mais adequados, em função do seu objetivo, o de formatar a percepção das coisas e do mundo, ou seja, o de conduzir o processo de formação da opinião pública, os autores destacam que os meios técnicos tendem eles próprios à uniformização. A televisão, por eles entendida como uma síntese da rádio e do cinema, poderá provocar um rápido e ainda maior empobrecimento dos materiais estéticos, porque o processo de elaboração do produto que integra palavra, som e imagem, o apresenta como um todo integrado. $O$ perigo reside na criação, tanto pela televisão quanto pelo cinema, da ilusão de um mundo que não é o imediatamente percebido, mas sim aquele cuja imagem interessa à indústria cultural em particular, e ao sistema económico e político, em geral, disseminar.

Uma ideia que surge em Adorno e Horkheimer é a da pré-existência do entretenimento e de alguns produtos da indústria cultural, relativamente ao seu aparecimento e que se manifestava pela arte popular, ou como eles designam, a «arte leve» em oposição à arte erudita ou clássica: esse tipo de arte era o equivalente funcional do entretenimento da cultura mercantilizada de hoje. Os autores alertam para o facto de, por vezes, ser difícil distinguir entre o fenómeno estético original, produto da arte erudita ou clássica, e a cópia que dele se faz, devido a uma espécie de absorção da arte leve na arte erudita, ou vice-versa, que ocorre no âmbito da indústria cultural em função dos interesses maiores do sistema, o lucro e a manutenção da ordem social. Para eles, contudo, e apesar de o idioma da indústria cultural se revelar cada vez mais «tecnicamente condicionado", a arte erudita distingue-se da arte popular na medida em que aquela se 
mantém fiel à ideia de verdade, enquanto esta se preocupa em responder aos interesses em função dos quais é produzida.

Ainda sobre a indústria cultural, uma questão relevante para os autores prende-se com o que designam de «estilo», sugerindo que em toda a obra de arte o estilo é uma promessa, e seja qual for a sua forma de expressão - palavra, som, imagem - ela deve reconciliar-se com o universal, de tal forma que o seu todo reflicta completa harmonia de seus elementos constitutivos. Mas isso acontece na obra de arte erudita, porque a falsa identidade entre o universal e o particular nas obras de arte popular, já anteriormente referida, elimina os focos de tensão porque as partes não interferem com a totalidade, podendo ser substituídas a qualquer momento sem que o todo se modifique substancialmente. Processo idêntico - de dissolução na falsa identidade da sociedade e do sujeito - se reflecte na acomodação do «elemento trágico» na arte popular: enquanto na arte erudita ele se associava à resistência dos heróis, na arte popular reduz-se à ameaça de destruição de quem não se integra nem coopera, o outsider. Para os autores, este facto não é de estranhar, porque na fase actual do desenvolvimento da humanidade a maioria das pessoas não é moralmente forte; pelo contrário, no capitalismo tardio a marca registada é a de individualidades fracas. Talvez por haver consciência dessa situação exista uma tão forte inclusão de violência e do sadomasoquismo na programação infantil, provavelmente com o objectivo de habituar as crianças, desde a mais tenra idade, à ideia de que os mais fortes batem nos mais fracos, exemplificados pelo Tio Patinhas e o Pato Donald da banda desenhada de Walt Disney (p. 110).

31 O elemento «sublimação» da obra de arte é analisado, uma vez mais, no confronto entre arte erudita e arte popular: enquanto o nu da obra clássica não se traduzia em exibição sexual, sobrepondo-se o seu sentido a qualquer apelo sensual que pudesse transmitir, a arte popular, no entender de Adorno e Horkheimer é «[...] ascética e sem pudor, a indústria cultural é pornográfica e puritana [...] reduzindo o amor ao romance [...] o que permite até mesmo a libertinagem [...] a produção em série do objecto sexual produz automaticamente o seu recalcamento» (p. 111). Neste trecho do livro, os autores dialogam com Freud, para quem a sublimação sempre esteve presente nas obras de arte erudita como um mecanismo de transposição da pulsão sexual para a esfera do espírito, conferindo-lhes um carácter essencialmente não-conformado, característica completamente ausente nas obras da arte popular.

Pegando neste ponto, o do conformismo essencial da indústria cultural, os autores relacionam-no com a ameaça de castração - outra categoria da psicanálise -, só que neste caso, exercida pelo sistema e não mais por uma pessoa, em geral próxima e querida (o pai). Para eles, esta característica da indústria cultural relaciona-se com a sua pretensão de liberdade sem limites, que lhe permite inclusive criticar o status quo não abrindo mão, contudo, da ameaça de castração. Antigamente, a ideologia era apenas veiculada pela palavra, através do discurso, das narrativas; hoje ela tem o mundo como seu objecto e as palavras tornaram-se supérfluas na medida em que as imagens e os sons mostram a verdade: «a indústria cultural derruba a objecção que lhe é feita com a mesma facilidade com que derruba a objecção ao mundo que ela duplica com imparcialidade. Só há duas opções: participar ou omitir-se» (p. 119).

33 Finalmente, uma outra ideia que se reflecte no argumento desta segunda parte do livro tem a ver com a transposição de um conceito que os autores vão buscar à teoria marxista. Marx designava de «feiticismo da mercadoria» o facto de ela esconder as 
condições das relações sociais que lhe deram origem. Adorno e Horkheimer afirmam que os objectos estéticos da indústria cultural estão sujeitos a uma inversão da «finalidade sem fim» atribuída por Kant às coisas belas da vida. O valor de uso - apesar de difícil de avaliar nas obras de arte - é absorvido pelo valor de troca, ou seja, em lugar de prazer estético, o que importa é «estar por dentro», o que vale é conquistar prestígio, só tem valor o que pode ser trocado e não por ser algo em si mesmo. «0 valor de uso da arte, seu ser, é considerado como um fetiche, e o fetiche torna-se o seu único valor de uso, a única qualidade atribuída por uma avaliação social que é erradamente entendida como hierarquia das obras de arte. É assim que o carácter mercantil da arte se desfaz ao se realizar completamente» (p.129).

\section{Elementos do anti-semitismo: Limites do esclarecimento} reflecte-se no argumento dos autores para este capítulo: o carácter sadomasoquista do grande público da indústria cultural é o pressuposto para a existência e desenvolvimento do anti-semitismo na sua versão nazista.

Das várias leituras possíveis, o ponto de vista liberal considera que os judeus constituem mais um grupo social com uma tradição religiosa específica, como tantos outros; para os nazistas, contudo, os judeus constituíam a anti-raça, sendo necessário o seu extermínio para bem da humanidade. Entretanto, a tese liberal esbarra no fato de tais grupos terem assimilado os pressupostos das diversas sociedades que os acolheram, em resultado da imbricação dialética entre esclarecimento e dominação.

Analisando as motivações do anti-semitismo, os autores referem motivos sociais, económicos e religiosos. Relativamente aos primeiros, consideram que a génese desse tipo de racismo na Alemanha se deve, por um lado, a fatores subjetivos: o projeto de dominação operou a exploração de sentimentos reactivos na população oprimida, direcionando-os para um «bode expiatório», os judeus, mantendo-a assim sujeita à opressão que lhe era infligida. Por outro lado, objetivamente, o grupo-alvo desse ódio aparecia aos olhos dessa população como próspero e feliz, apesar de não possuir nenhuma influência política nem poder de comando, o que suscitava suspeitas e acirrava os ódios. Do ponto de vista dos motivos económicos, o grupo-alvo também correspondia exactamente aos objectivos dos dominadores: devido à proibição de intervir no sector industrial produtor da mais-valia, as suas actividades económicas situavam-se no sector terciário e financeiro, especialmente no sector bancário, o que na época da hiper-inflação que a Alemanha atravessava, permitiu relacionar os judeus com a imagem de exploradores, quando na verdade eram meros executores de tal exploração, devido à falência do sistema produtivo alemão.

Relativamente às motivações religiosas, a situação dos judeus era, também, peculiar na Alemanha da República de Weimar: os seguidores da religião dominante, cristãos, associavam a felicidade desprovida de poder que os judeus evidenciavam, com o carácter da sua religião, mais próxima da auto-conservação e não recorrendo aos sacrifícios impostos pelo cristianismo, o que foi explorado pelos líderes fascistas, acirrando o ressentimento dos proletários alemães dirigido a estes estrangeiros que tinham melhor situação económica que eles. 
Retomando uma das características anteriormente referidas, a da propensão natural de pessoas e grupos procurarem assemelhar-se às que as rodeiam, facilitando a sua integração no entorno, os autores defendem a ideia de que esta reação, embora natural nas pessoas em geral, tem consequências distintas em função da formação e da capacidade das pessoas em discernirem ou agirem por si próprias, ou não. Neste último caso, esse comportamento mimético pode conduzir a uma patologia social o que explica que, na Alemanha, os que não se exilaram, submeteram-se ao regime fascista e absorveram todas as suas taras, entre as quais, a da sua superioridade racial em termos de saúde. Por essa razão, para além de representarem a anti-raça, os judeus apresentavam um carácter doentio que era preciso eliminar da sociedade.

Como existia esta mimésis do "saudável» usada pelos fascistas com objetivos de dominação, existia também o que os autores designam de «comportamento projectivo» no âmbito da sua teoria da falsa projeção: a percepção da realidade por parte de sujeitos mal constituídos e empobrecidos, tanto económica quanto espiritualmente, é redutora porque, devido à ausência de meios de elaboração, eles reduzem-na à percepção que fazem de si próprios, ou seja, os anti-semitas viam o judeu (ou quem fosse diferente, em geral) como alguém pernicioso cuja eliminação só traria a felicidade e o bem para a sociedade. Esta semi-cultura, resultante de uma percepção equivocada da realidade, serviu aos interesses dos fascistas, que a trabalharam através da cultura de massas visando o seu empobrecimento mais acentuado.

A utilização de todas estas motivações pelos líderes fascistas alemães, produziu como que uma unanimidade em torno da rejeição dos judeus pela sociedade. Segundo os autores, isto foi alcançado graças ao que designam de «mentalité do ticket», ou seja, a aceitação activa ou passiva de uma lista de propostas e candidatos, por eleitores despreparados, desatentos e dominados, sendo este mesmo consumo «cego» o que se regista em relação aos produtos da indústria cultural: o espectador aceita-os para se sentir inserido, parte do ambiente que o rodeia, em conexão com o mundo.

\section{NOTAS}

1. Cf. p. XII, prefácio dos autores à edição de 1969.

2. Cf. p. XI, prefácio dos autores à edição de 1969.

3. Cf. p. XII, prefácio dos autores à edição de 1969.

4. A horda como os autores designam. 


\section{AUTOR}

\section{CESALTINA ABREU}

tinaabreu@yahoo.com.br

tinaabreu@hotmail.com

Professora Auxiliar do Departamento de Sociologia da Faculdade de Ciências Sociais (FCS) da Universidade Agostinho Neto (UAN) e chefe do referido departamento.

Doutorada em Sociologia (2006) e mestre (2001) pelo Instituto Universitário de Pesquisas do Rio de Janeiro (IUPERJ), República Federativa do Brasil. É licenciada em Agronomia (1977) pela Universidade de Luanda (curso superior de Agronomia, Huambo). A sua dissertação de mestrado intitula-se Participação faz diferença? Reflexões na avaliação do Fundo de Apoio Social (FAS) no Sudoeste de Angola (Huíla, Namibe e Kunene); e a tese de doutoramento tratou da Sociedade civil em Angola. Da realidade à utopia. Obteve o Certificado em estudos avançados em prática académica (CASAP), Módulos 1 e 2, na Universidade de Newcastle (2013), Grã Bretanha. É actualmente Professora Auxiliar e Chefe do Departamento de Sociologia da Faculdade de Ciências Sociais (FCS) da Universidade Agostinho Neto (UAN) e docente convidada do Curso de Mestrado em Ordenamento e Planeamento de Áreas Urbanas do Departamento de Arquitectura da Faculdade de Engenharia da UAN. As suas áreas de interesse no âmbito da Sociologia Política envolvem questões multidimensionais da cidadania, análise de contexto, abordagens de «desenvolvimento», sustentabilidade e ambiente, capital humano e social, participação, direitos humanos e justiça social, cultura cívica, espaço público e sociedade civil, memória social, confiança e tolerância. Publicou entre outros os materiais seguintes: a) em capítulo de livros: «Cidadania e participação em Angola. Que papel para a sociedade civil?», in Boaventura de Sousa Santos e José Octávio Serra Van-Dúnem (orgs.), Sociedade e Estado em construção: desafios do Direito e da Democracia em Angola - Luanda e Justiça: pluralismo jurídico numa sociedade em transformação, volume I. Coimbra, Almedina, 2012, pp. 369-403; «Angola, SADC e a globalização», in Jonuel Gonçalves (org.), Atlântico Sul XXI. América do Sul e África na virada do milénio. São Paulo, Editora Unesp, pp. 185-207; «A sociedade civil em Angola e seus desafios internos e externos», in Nuno Vidal e Justino Pinto de Andrade, Sociedade civil e política em Angola. Enquadramento regional e internacional, Luanda e Lisboa, Edições Firmamento e Média XXI, 2008, pp. 101-114; b) artigos e comunicações publicadas: «Em busca da (re)organização da vida em Angola», comunicação ao I Colóquio da Faculdade de Ciências Sociais da Universidade Agostinho Neto, Luanda, 25-26 Outubro 2011, Mulemba - Revista Angolana de Ciências Sociais, vol. II , n. 3, Maio 2012, pp. 103-127; «Desigualdade social e pobreza: ontem, hoje (e que) amanhã?», RAS Revista Angolana de Sociologia (Luanda), n. 9, Junho de 2012, pp. 93-111; «Pobreza em Angola: percepções, acção colectiva e os dilemas de participação com base numa pesquisa qualitativa», comunicação apresentada à I Conferência Internacional do IMETRO sobre Gestão das cidades, intervenção tecnológica e combate à pobreza, Luanda, 23-24 Junho 2011 [material não publicado]. 